\title{
Observações sobre os impactos hidrológicos na barragem do rio maranguapinho em Maranguape-CE
}

\author{
Notes on the hydrologic impacts on the Maranguapinho river dam in Maranguape-CE
}

\author{
Veras $^{1}$, P. M. C.; Mendonça ${ }^{2}$, B. H. S.; Ferreira ${ }^{3}$, Y. B. \\ pedroufcgeo@gmail.com
}

\begin{abstract}
Resumo
$\mathrm{O}$ presente artigo visa fazer uma analise parcial dos impactos hidrológicos na barragem do Rio Maranguapinho localizada no município de Maranguape-CE correlacionando os fatores de qualidade da água e as dinâmicas socioambientais das áreas adjacentes. Essa pesquisa ocorreu através da coleta de dados de órgãos governamentais referentes a recursos hídricos no estado do Ceará, visita a área estudada, uso do conhecimento teórico já obtido e consulta a bibliografia referente ao assunto. O trabalho tem por intuito refletir sobre o potencial hídrico dessa barragem para o município de Maranguape-CE e o uso atual da mesma tendo em vista as condições climatológicas do nosso estado e região nesse grande período de seca e mais especificamente no próprio município onde se localiza esse reservatório. O "Projeto Rio Maranguapinho" teve a maioria dos seus objetivos alcançados e maioria destes foi a jusante da barragem. $\mathrm{O}$ planejamento ambiental de recuperação do rio não alcança os setores a montante da barragem. As áreas próximas a barragem tem carência de saneamento básico e as áreas mais afastadas poluem os trechos urbanos dos rios tributários com inúmeros esgotos clandestinos resultando aceleração dos processos de eutrofização e na diminuição da qualidade da água.
\end{abstract}

Palavras-chave: Barragem, Rio Maranguapinho, Sistema Sanitário.

\begin{abstract}
This article aims to make a partial analysis of the hydrologic impacts on the Maranguapinho River dam located in Maranguape-CE municipality correlating water quality factors and environmental dynamics of the surrounding areas. This research took place through the collection of government agencies of data on water resources in the state of Ceará, visit the study area, using theoretical knowledge already obtained and consulting the literature on the subject. The work is meant to reflect on the water potential of this dam for Maranguape-CE municipality and the current use of the same in view of the climatic conditions of our state and region in this great drought and more specifically in the city itself where it is located this reservoir. The "Project Rio Maranguapinho" had achieved most of its objectives and most of these were downstream of the dam. Environmental planning of river recovery does not reach the sectors upstream from the dam. The areas near the dam have lack of basic sanitation and the most remote areas pollute the urban stretches of the tributaries with numerous illegal sewage resulting acceleration of eutrophication processes and decreased water quality.
\end{abstract}

Keywords: Dam, Rio Maranguapinho, Sanitary system.

\section{INTRODUÇÃO}

Atualmente a questão da disponibilidade e gestão dos recursos hídricos, poluição do ambiente, degradação ambiental, conservação da natureza e preservação são temas debatidos mundialmente, esses problemas geralmente são causados ou influenciados pela ação antrópica. Tudo isso pode estar relacionado com a falta de planejamento ambiental, uso e ocupação do solo, educação ambiental e poder público. Algumas regiões do mundo sofrem com questão dos recursos hídricos seja pelo clima da região, seja pela escassez da água e principalmente por sua má gestão. Com a ação antrópica do homem esse processo acelerou-se e vem ganhando força a cada dia. A degradação da natu- 
reza em si só se torna uma degradação dos recursos hídricos quando destrói matas ciliares (e também matas ao longo das bacias e microbacias em geral, pois a mesma seria de grande importância para a conservação do solo, umidade e a retenção da água que se infiltraria para os aquíferos reabastecendo o rio) e de uma forma geral na ausência do saneamento básico tendo em vista que vários tipos de resíduos líquidos (Vazamentos de fossas, oleodutos e esgotos, depósitos de combustíveis e pesticidas e Infiltração de Água contaminada no lençol freático através de rios contaminados e chuvas contaminadas alem de estoque e aplicação agrotóxicos) e sólidos (Deposito de resíduos tóxicos, deposito de rejeitos sanitários e lixo e depósitos de combustíveis e pesticidas e aplicação de adubos) podem ser extremamente prejudiciais ao meio ambiente.

Em se tratando da realidade do município de Maranguape, com base nesse contexto sobre a degradação dos recursos hídricos, faz-se uma análise geoambiental da Barragem do rio Maranguapinho no município de Maranguape-CE que é uma localidade urbana no bairro Novo Maranguape II na sede do Município, localizada à aproximadamente 18 quilômetros do município de Fortaleza-CE. A barragem do rio Maranguapinho situada entre Maranguape e Maracanaú foi concluída em 2014 pela Secretaria das Cidades do Estado do Ceara e o principal propósito da mesma foi à contenção das cheias do rio Maranguapinho com o intuito de melhorar a vida da população que reside às margens do rio (faixa de alagamento) a jusante da mesma. O projeto também visa revitalizar as áreas ao entorno do rio (através de limpezas e limitação de suas faixas de preservação). No entanto essa revitalização só ocorrerá na faixa que segue a jusante da barragem nos municípios de Maracanaú e Fortaleza. Toda a água que se acumula na barragem passa através da sede de Maranguape e por sua vez todo esse caminho já existe uma quantidade considerável de poluição devido à urbanização dos bairros, e a existência de indústria e comercio o que justifica o fato de tal corpo hídrico estar atualmente classificado como hipereutrófico segundo a FUNCEME/COGERH. De maneira singular algumas áreas ao longo da microbacia do rio Maranguapinho também sofrem com a perda de vegetação nativa, assoreamento, despejo de esgotos além é claro de pequenas barragens ao longo dos sítios (na serra de Maranguape) desde as nascentes dos rios até as áreas mais rebaixadas dos maciços. Podemos nos referir a esse estudo mais especificamente ao alto curso dos riachos Pirapora e Gavião (rios tributários).

O município de Maranguape está localizado na microrregião de Fortaleza, bem como na região metropolitana do de Fortaleza. A distância até a capital em linha reta é de $26 \mathrm{~km}$, sua área é de 590,824km² e tem como municípios limites: Caucaia-CE, Maracanaú-CE, Palmácia-CE, CaridadeCE, Guaiuba-CE, Pacatuba e Pentecoste-CE. A sede do município tem uma altitude de aproximadamente 68 metros. As coordenadas geográficas são de 03 Graus 53’ Minutos 2" segundos de latitude sul e $38^{\circ}$ graus $41^{\prime}$ minutos e $09^{\prime \prime}$ segundos de longitude oeste. 
Esse município está dividido além de sua sede em 17 distritos: Amanari, Antônio Marques, Cachoeira, Itapebussu, Jubaia, Lages, Lagoa do Juvenal, Manoel Guedes, Papara, Penedo, São João do Amanari, Sapupara, Tanques, Ladeira Grande Umarizeiras e Vertentes do Lagedo.

\section{METODOLOGIA}

Foram realizados levantamentos de dados dos órgãos públicos Cogerh, Funceme e Secretaria das Cidades do Estado do Ceará através das informações disponibilizadas ao público em diversos endereços eletrônicos como, por exemplo, sobre a qualidade da água, através do Portal Hidrológico do Ceará, onde estão disponibilizados os diagnósticos de grande parte dos corpos hídricos do Estado que tratam desde níveis tróficos até o volume de água armazenado e também notícias com informações sobre o Projeto Rio Maranguapinho nos portais oficiais do governo e jornais locais. Além do conhecimento teórico já obtido usamos uma seleção bibliográfica de autores que tratam da temática em estudo complementando as observações com pontos de vista como o geomorfológico e o hidrológico além de observações químicas e biológicas. Identificamos e delimitamos a área de trabalho de acordo com as drenagens do relevo e locais que tem uma relação influente na dinâmica do corpo hídrico em estudo. Fizemos visitas com o intuito de reconhecimento de campo nos limites nos bairros mais próximos a barragem e em toda a sua extensão paralela a mesma, incluído nesse roteiro de campo também visitamos a área aberta da barragem. Durante essas visitas coletamos material através de anotações, visualização dos locais e fotos que proporcionaram a discussão e reflexão sobre o desenvolvimento dessa pesquisa e também o material que se encontra disponível no mesmo relatório.

\section{RESULTADOS E DISCUSSÃO}

O projeto que deu origem a essa barragem que ficou conhecido como "Projeto Rio Maranguapinho" foi uma obra de grande porte e na época foi considerada a maior obra de intervenção urbana prevista no programa de aceleração do crescimento (PAC) alem de ser um projeto finalista do “premio ANA 2012” uma das maiores premiações a nível nacional relacionada a recursos hídricos promovida pela Agencia Nacional das Águas. Suas obras tiveram inicio no ano de 2007 e foram concluídas no ano de 2014. A barragem em si é uma parte do todo mais sem ela seria inviável todo o restante do projeto, ela tem uma área de cerca de $3 \mathrm{~km}^{2}$ e suporta um volume de $9.350 .000 \mathrm{~m}^{3}$. O principal objetivo da construção da barragem foi à diminuição da faixa de alagamento e conseqüentemente das áreas de risco do Rio Maranguapinho em Fortaleza que correspondiam a 50\% do total de áreas de risco no município. O restante do projeto se tratava de recuperação das faixas de preser- 
vação do rio (a jusante da barragem), urbanização, saneamento básico e moradia através da construção de condomínios residenciais para as famílias que residiam nas áreas adjacentes ao rio. Os recursos totais investidos no projeto são estimados em cerca de 462 milhões de reais que mais tarde receberiam o investimento de mais 232 milhões para ampliação do projeto. Cerca de 85 milhões foram destinados a construção da barragem segundo a Secretaria das Cidades do Estado do Ceará.

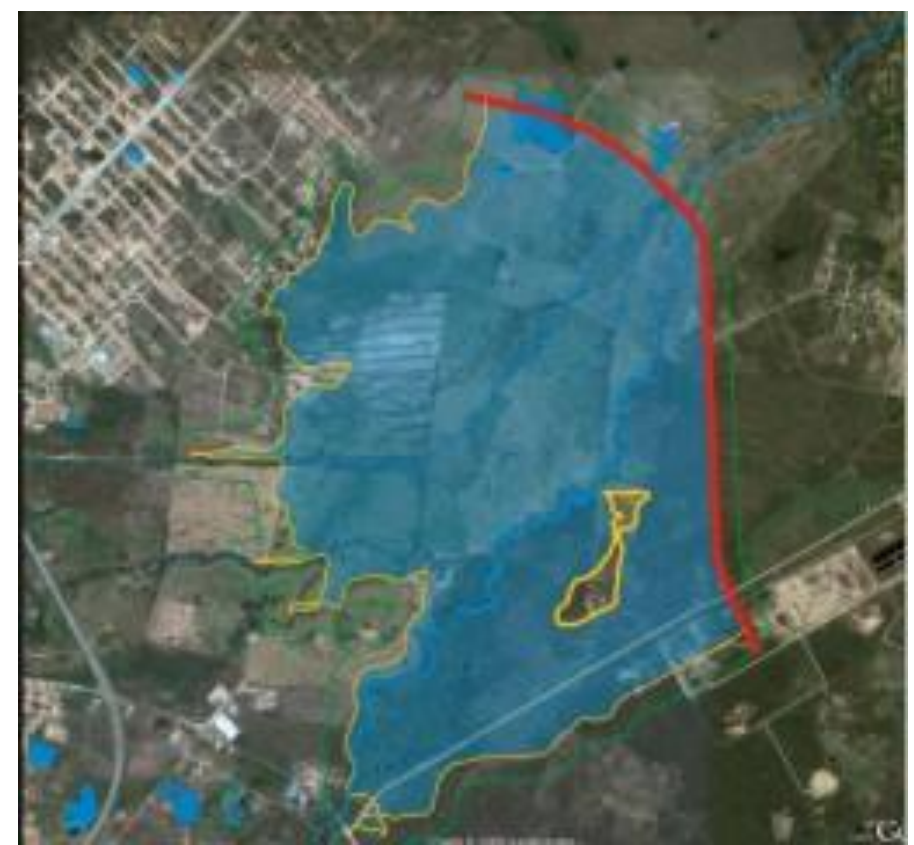

Figura 01. Projeto da Barragem Rio Maranguapinho. Fonte. Secretaria das Cidades do Estado do Ceará (2007)

A barragem esta posicionada paralelamente aos bairros Novo Maranguape I e II, Cônego Raimundo Pinto e a Serra de Maranguape na direção leste. A drenagem dos terrenos tem seu sentido de noroeste a suldeste levando em consideração o rampeamento do maciço residual. O bairro que esta mais próximo é o Novo Maranguape II onde a distancia do inicio do bairro (CE 065) até a barragem fica em torno de 1,5km. Quanto mais se adentra no bairro mais se nota a disponibilidade de imóveis em construção e recém construídos a venda. A maioria são casas simples para famílias de classe media. A expansão imobiliária acontece de forma natural (Sem grande influencia de um fator externo) por esse bairro ser próximo ao centro. A infra-estrutura não acompanha essa expansão. A maioria dessas ruas não tem pavimentação nem saneamento básico. Em meio a varias habitações populares surgem alguns imóveis em péssimas condições físicas às vezes estando agrupados em pequenos conjuntos e/ou próximos a esgotos. A falta de saneamento básico forma diversos canais de esgoto a céu aberto que seguem sua drenagem para a barragem onde não é possível a visualização do contato devido à grande quantidade de macrófitas que pode ser vistas na figura 02 . 


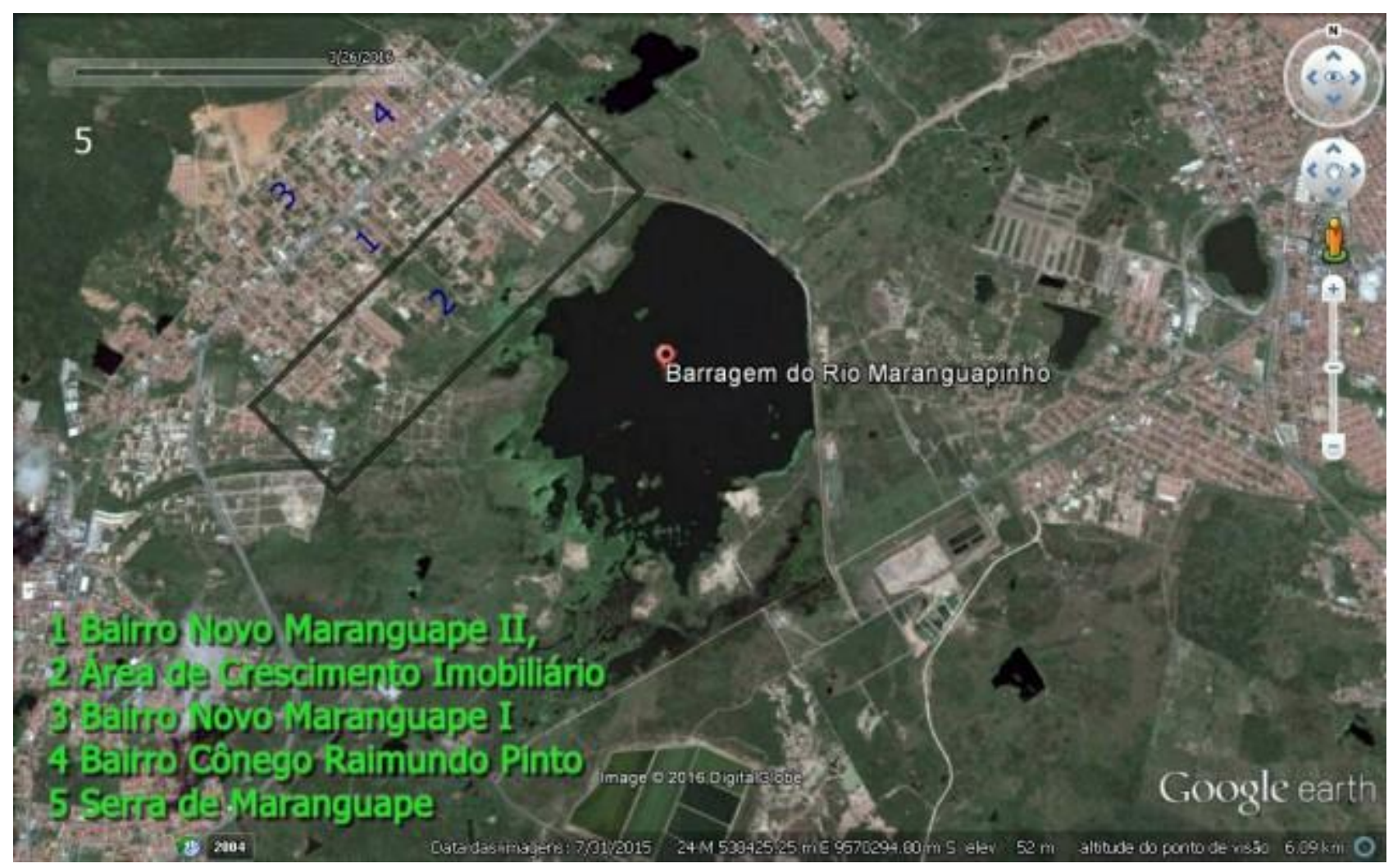

Figura 02. Barragem do Rio Maranguapinho e bairros adjacentes. Fonte. Google Earth (2016)

Segundo dados da Fundação Cearense de Meteorologia e Recursos Hídricos (FUNCEME) e da Companhia de Gestão dos Recursos Hídricos (COGERH) disponíveis no portal hidrológico do Ceará, o estado trófico da água é classificado como hipereutrófico. Esteves (1988) afirma que a eutrofização é o aumento da concentração de nutrientes, especialmente fósforo e nitrogênio, nos ecossistemas aquáticos, que tem como consequiência o aumento de sua produtividade. Esse processo de eutrofização dos corpos hídricos é algo comum em longo prazo sendo visto como uma evolução natural do ecossistema, porém com os fatores antrópicos o esse crescimento é acelerado. As estimativas apontam que a transição de um corpo hídrico de oligotrófico para eutrófico/hipereutrófico de forma natural acontece numa escala de séculos enquanto com a influência antrópica acontece em décadas.

Tabela 01. Características da água da Barragem do Rio Maranguapinho Fonte. COGERH (2015/2016)

\begin{tabular}{|c|c|c|c|c|l|}
\hline \multicolumn{7}{|c|}{ Barragem do Rio Maranguapinho } \\
\hline Data & $\begin{array}{c}\text { Nitrogênio } \\
(\mathbf{m g} / \mathbf{L})\end{array}$ & $\begin{array}{c}\text { Fósforo total } \\
(\mathbf{m g} / \mathbf{L})\end{array}$ & $\begin{array}{c}\text { Cloroflila } \mathbf{- a} \\
\mathbf{( \mu g} / \mathbf{L})\end{array}$ & $\begin{array}{c}\text { Cianobacterias } \\
\mathbf{( C e ́ l / m L )}\end{array}$ & Estado Trófico \\
\hline $\mathbf{j u n} / \mathbf{1 5}$ & 2,211 & 0,542 & 113,21 & 214 & Hipereutrófico \\
\hline $\mathbf{s e t} / \mathbf{1 5}$ & 1,674 & 0,203 & 58,3 & 563,744 & Hipereutrófico \\
\hline $\mathbf{d e z} / \mathbf{1 5}$ & 3,153 & 0,265 & 135 & 455 & Hipereutrófico \\
\hline $\mathbf{m a r} / \mathbf{1 6}$ & 2,655 & 0,391 & 99,86 & 478 & Hipereutrófico \\
\hline Média & 2,42325 & 0,35025 & 101,5925 & 428 & Hipereutrófico \\
\hline
\end{tabular}


A tabela acima apresenta algumas características da água da barragem que é administrada pela Companhia de Gestão dos Recursos Hídricos (COGERH) e tem os dados disponibilizados no portal hidrológico do Ceará. A qualidade da água barragem não precisa ter altos padrões de pureza tendo em vista que o propósito da mesma é de contenção. Porem alguns padrões básicos (resolução ${ }^{\circ} 357$, de 18 de março de 2005) para água doce (Classe I) do Conselho Nacional do Meio Ambiente (CONAMA) mostram que a quantidade de clorofila-a esta extremamente acima do limite básico estabelecido que é de $10 \mu \mathrm{g} / \mathrm{L}$, O nível de fósforo total ultrapassa os 0,020 miligramas por litro estabelecidos para ambientes lênticos (águas paradas ou semi-paradas), o nitrogênio esta abaixo do limite dos 3,7 miligramas por litro assim como o nível de cianobactérias que não se aproxima das $20.000 \mathrm{Cél} / \mathrm{mL}$ permitidas. Nos padrões para pesca ou cultivo de organismos (Classe II) os níveis de Clorofila-a, Fósforo total estão acima do limite permitido e os índices de nitrogênio e cianobactérias estão consideravelmente abaixo do limite Maximo.

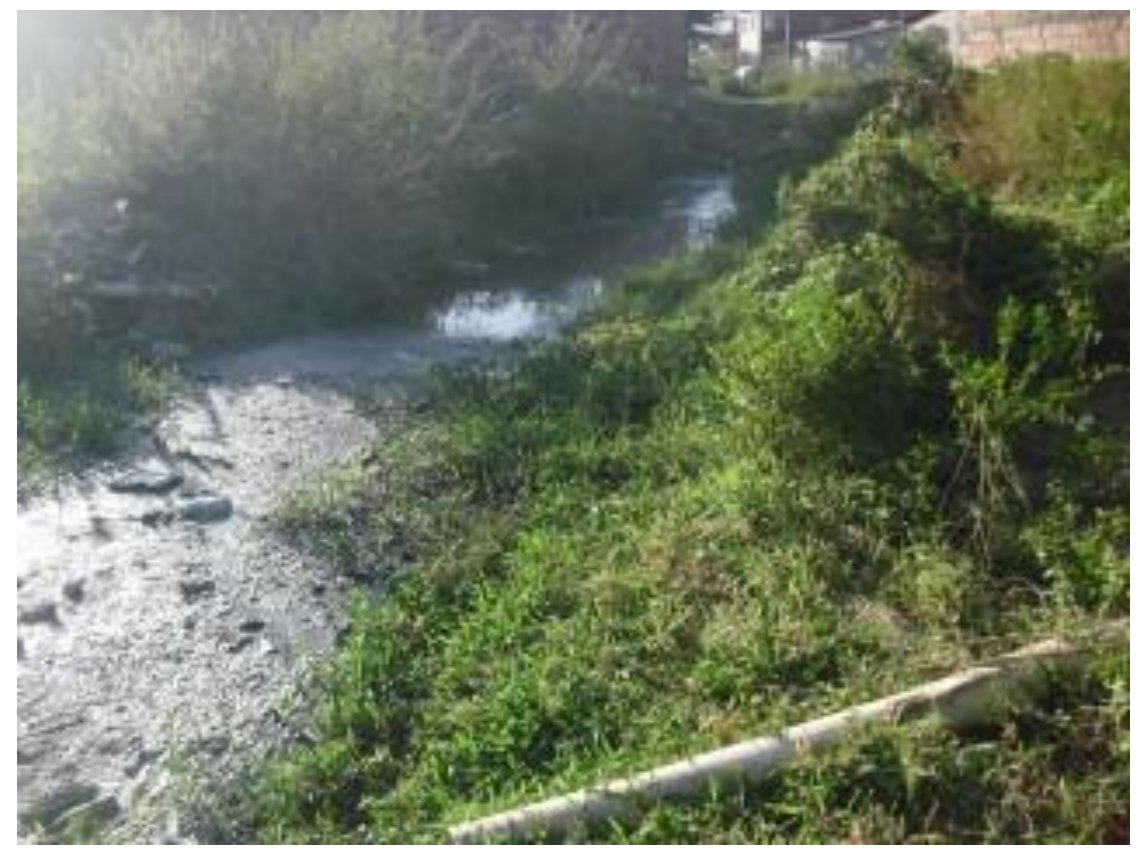

Figura 03. Canal de esgoto céu aberto (Bairro Novo Maranguape II). Fonte. Veras (2016)

Nas observações apresentadas às águas da barragem do rio Maranguapinho apesar de apresentar resultados iguais nas comparações com as classes I e II segundo os parâmetros da CONAMA, seriam mais adequadas a classe II (apesar de ter valores acima do Maximo) que se destina a pesca amadora e a recreação de contato secundário (o que atualmente acontece na área "aberta" da barragem) e a classe III que se destina a navegação e harmonia paisagística. A presença de elementos químicos como o fósforo é impulsionada por fatores antrópicos significativos sendo os esgotos clandestinos um dos que mais contaminam pela sua carga continua em um ambiente de águas lênticas. Essa situação acarreta no que pode ser chamado de eutrofização artificial (enriquecimento de nutrientes, principalmente de nitrogênio e fósforo). A figura 03 mostra um exemplo de esgoto a céu aberto no 
bairro Novo Maranguape II. Esse é um dos canais que seguem sua drenagem com destino a barragem do Rio Maranguapinho.

Alem das características químicas da água é necessário levar em consideração que a construção de uma barragem muda a dinâmica do sistema fluvial a montante, jusante e no próprio reservatório ou barragem. Coelho (2007) e Fontes (2002) apontam a amplitude espacial dos impactos da construção de barragens a nível local, regional e de bacia hidrográfica (e microbacia) numa escala temporal que varia entre imediato, médio e longo prazo. A intervenção humana de grande intensidade (Barragem) no curso de um rio gera o rompimento do equilíbrio longitudinal de um rio e altera o seu sistema lótico (correntezas) diminuindo a velocidade das águas e tornando-as semi-paradas na barragem e a jusante da mesma. São diversos os impactos hidrológicos e geomorfológicos nos diferentes setores do sistema fluvial (montante, barragem e jusante) que podem ser discutidos. Cunha (1995) aponta alguns exemplos de impactos hidrológicos (como alterações na estrutura térmica da água, nas dinâmicas de transporte e deposição sedimentar e na velocidade das correntezas) e Geomorfológicos (Assoreamento em diferentes setores, formação de novas áreas de inundação, Formação de bancos de areia, alterações nos níveis de base locais, reajuste na morfologia do canal e alterações na dinâmica da foz).

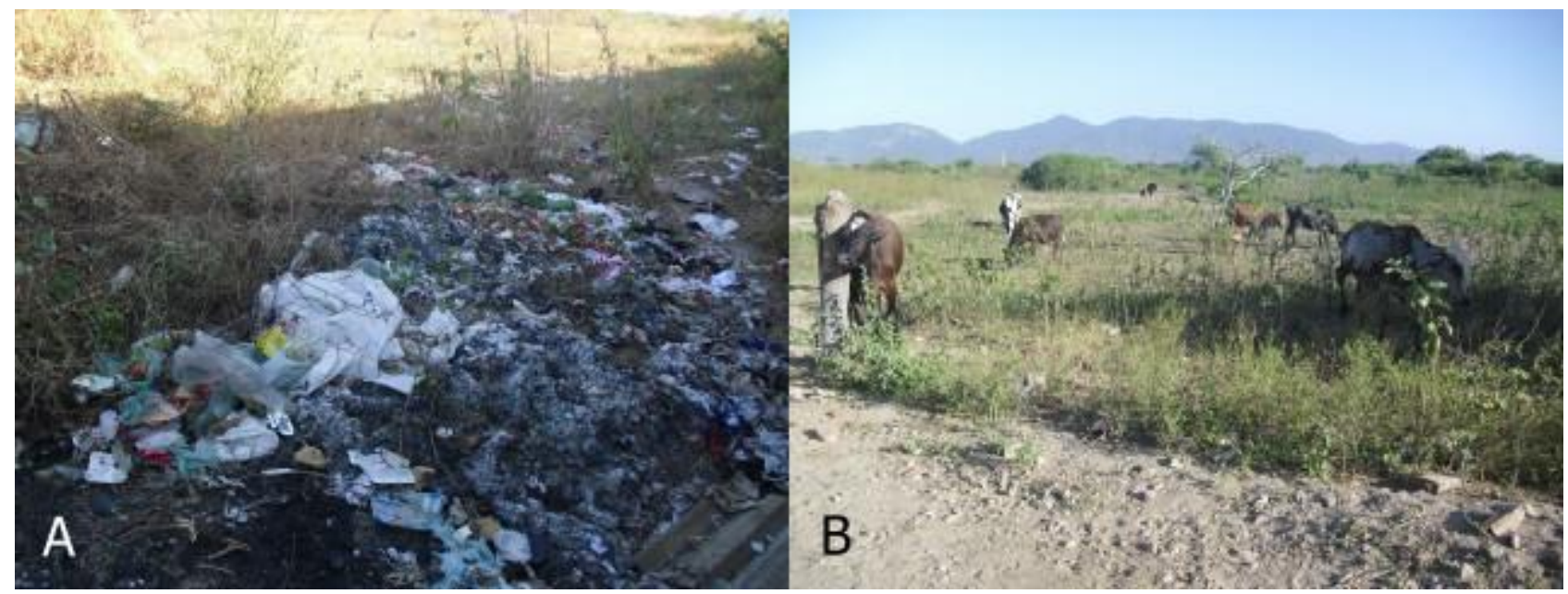

Figura 04. A) Lixo queimado na área interna da Barragem. B) Pastagem de bovinos na área interna da barragem

Fonte. Veras (2016)

A maior parte da barragem pode ser acessada por banhistas e pescadores. Nos limites que correspondem ao lado do bairro Novo Maranguape II o acesso varia entre algumas estradas de terra, trilhas através da mata, por propriedades privadas, cercas ou grandes espaços abertos em muros limítrofes. A entrada principal onde se tem acesso ao muro de contenção e ao sangradouro é protegida por seguranças (de empresa terceirizada) que fazem rondas de moto durante o dia nas áreas internas da barragem e só permitem pessoas com autorização, Geralmente funcionários da COGERH que é o 
órgão do governo quem gerencia a barragem. Nos limites entre o fim do bairro Novo Maranguape II e o começo da barragem existem em alguns pontos criações de bovinos (algumas vacarias) e eqüinos (dispersos). Os bovinos costumam se locomover durante o dia nas proximidades da barragem onde se alimentam e matam a sede. Nesses limites também entre bairro e área de barragem existem alguns campos de futebol improvisados utilizados como área de lazer e recreação. Alguns pontos são usados como deposito de lixo que por vezes é queimado no próprio local como mostra a figura $04 \mathrm{~A}$.

\section{CONSIDERAÇÕES FINAIS}

A construção da barragem do rio Maranguapinho e a proposta do projeto geral de revitalização trazem um questionamento sobre a atual situação ecológica da microbacia a montante da barragem e a questão do saneamento básico nos bairros adjacentes. Existem também problemas poluição nos riachos percorrem na sede do município de Maranguape e deságuam na barragem onde essa água se acumula, já que não serão beneficiados com a revitalização do projeto (que é a jusante da barragem) e estão sendo degradados de múltiplas maneiras. Tal barragem uma vez que recebe água poluída não pode ser utilizada para a população e a mesma poderia ser um bem hídrico para a cidade tendo em vista que vários distritos de Maranguape têm sofrido com a seca e esse é o maior corpo hídrico do município. Temos que pensar na água como um bem hídrico de alto valor e investir na idéia de preservação em longo prazo. Afinal de contas a região que vivemos e o clima tornam essa idéia praticamente obrigatória. Existem alguns estudos sobre a situação de alguns rios e riachos de Maranguape (microbacias), porém a barragem é um novo fator que merece atenção pelos fatos já mencionados. Apesar de sua conclusão em 2014 a mesma recebeu parte do volume inicial de água no período de fevereiro e maio de 2012.

A importância do estudo está em saber quais processos ocorrem devido à atual situação ecológica dos riachos e qual a sua influencia na barragem do rio Maranguapinho. Se houver um estudo de analise geoambiental aprofundado e propostas de revitalização do rio nessas áreas urbanas além é claro da barragem, há a possibilidade de melhorar a qualidade da água em longo prazo preservando os trechos dos rios e diminuindo a possibilidade de doenças devido à poluição e principalmente tornar limpa a água que se acumula na barragem receptora, não só para amenizar o impacto das enchentes em fortaleza como já ocorre atualmente mais também para ser usado como opção de abastecimento para a população de Maranguape (distritos atingidos pela seca) e aumentar a qualidade da água de forma geral. Em um dos maiores projetos de intervenção urbana (com proposta de revitalização do rio) que foi finalista de um prêmio de reconhecimento nacional e trabalhou com recursos de quase 700 milhões de reais o alto e médio curso a montante da barragem (em geral toda micro- 
bacia do Rio Maranguapinho) não foram levados em consideração ou as analises não foram suficientes para resolver ou perceber a situação ecológica do rio e os problemas de saneamento básico nos bairros adjacentes que aliados ao sentido da drenagem acumulam dejetos líquidos no reservatório e contribuem pra continuação aumento dos processos de eutrofização e a poluição das águas no reservatório. Apesar dessas características específicas no município de Maranguape o projeto conseguiu amenizar a faixa de alagamento do rio maranguapinho em fortaleza e melhorar significativamente a vida da população dessas áreas de risco (onde a maioria eram pessoas de baixa renda e viviam em condições de habitação precárias) fornecendo uma melhor estrutura urbana, equipamentos de lazer e principalmente habitações adequadas para a população local.

\section{REFERÊNCIAS}

Agencia Nacional Das Águas (Org.). Projeto Rio Maranguapinho: Premio Ana 2014. 2014. Disponível em: <http://premio.ana.gov.br/Edicao/2014/projetodetalhe.aspx?id=18\&\$ListID=A2CB8C6D-6FE2-4E67-BD57-5254DBCF88DD> . Acesso em: 21 jul. 2016.

BRASIL. Constituição (2005). Resolução n 357, de 17 de março de 2005. Classificação dos Corpos de água: diretrizes ambientais para o seu enquadramento. Brasil, 18 mar. 2005. Seção 1, p. 6-13. Disponível em: <http://www.mma.gov.br/port/conama/res/res05/res35705.pd>. Acesso em: 26 jul. 2016.

COELHO, André. L. N. Alterações hidrogeomorfológicas no Médio-Baixo Rio Doce/ES, 2007.

237 f. Tese de Doutorado (Instituto de Geociências, Programa de Pós-Graduação em Geografia, Universidade Federal Fluminense) UFF, Niterói - Rio de Janeiro, 2007

CUNHA, Sandra B. Impactos das Obras de Engenharia Sobre o Ambiente Biofísico da Bacia do Rio São João (Rio de janeiro - Brasil). Rio de Janeiro: Ed: Instituto de Geociências, UFRJ, $1995.378 \mathrm{p}$.

ESTEVES, F.A. Fundamentos de Limnologia. Rio de Janeiro: Editora Interciência, 1988. 574p FONTES, Luiz C. S. Erosão Marginal no Baixo Curso do Rio São Francisco. Um Estudo de Caso de Impactos Geomorfológicos à Jusante de Grandes Barragens, 2002. 249 f. Dissertação (Mestrado em Desenvolvimento e Meio Ambiente) - Núcleo de Pós-Graduação e Estudos do SemiÁrido Programa Regional de Pós-Graduação, Universidade Federal de Sergipe) UFS, Aracaju Sergipe 2002.

FREIRE, Cleuda Custódio. Qualidade da água. In: BRASIL. AGENCIA NACIONAL DAS ÁGUAS. . Curso de aperfeiçoamento em gestão de recursos hídricos: Princípios de hidrologia 
ambiental. Florianópolis: Universidade Federal de Santa Catarina e Universidade Federal de Alagoas, 2005. Cap. 10. p. 143-159.

FUNCEME. Sistema de Qualidades das Águas. 2016. Disponível em:

<http://www.hidro.ce.gov.br/acude/eutrofizacao>. Acesso em: 18 jul. 2016.

MARANGUAPE. Ipece. Governo do Estado do Ceará (Org.). PERFIL BÁSICO MUNICIPAL

2013 MARANGUAPE. 2013. Disponível em:

<http://www.ipece.ce.gov.br/publicacoes/perfil_basico/pbm-2013/Maranguape.pdf>. Acesso em: 18 jul. 2016

Recebido em: 14/08/2016

Aceito para publicação em: 01/10/2016 